\title{
Aerobatic Flight Training for U.S. Commercial Pilot Applicants: Should it be Mandatory?
}

\author{
Joseph J. Vacek \\ University of North Dakota
}

\begin{abstract}
Commercial pilot applicants in the U.S. are not required to have any aerobatic training. Sometimes airplanes flown by these pilots encounter weather, turbulence, or other factors that can cause loss of control. When an aircraft is out of control and in an extreme unusual attitude, the flight controls respond differently. If the pilot is not familiar with aerobatics, an accident can result.

Since pilots have a vested interest in improving the safety of the aviation industry, the hypothesis was that pilot attitudes would be favorable towards mandatory aerobatic training for the issuance of a commercial pilot certificate. Other industry professionals and literature review support the notion that aerobatic training would (or does) improve aviation safety.

A survey designed to measure quantitative and qualitative attitudinal data on a 4 item forcedresponse Likert scale was used to measure the correlation of pilots' aerobatic experience with their confidence levels. Also measured were open-response items addressing comments or concerns voiced by the subjects. There was significant correlation of the pilots' aerobatic experience level to increased confidence levels. Also, the participants all indicated that aerobatic training would or has made them safer pilots. Thus, the findings support the hypothesis that pilots would be in favor of mandatory aerobatic training for the issuance of a US commercial pilot's license.
\end{abstract}

\section{INTRODUCTION}

In order to become a licensed pilot in the United States, a person must receive 20 hours of flight training from a certified instructor pilot, and accomplish 10 hours of solo flight (14CFR 61.109). The training and soloing consist of learning how to properly plan a flight, takeoff and land, perform certain in-flight maneuvers, and navigate (14CFR 61.107b). All tasks are performed in visual meteorological conditions, meaning that the pilot controls the aircraft primarily by looking outside of the aircraft. This minimal amount of training is required for a private pilot certificate. Next the pilot learns to control the aircraft using only instrument reference, flying without outside reference. This training earns the pilot an instrument rating. Finally, a pilot trains to become a commercial pilot, when he or she can carry passengers for hire. It takes a minimum of 250 hours of flight time to become a commercial pilot (14 CFR 61.129a). The commercial pilot is allowed by the Federal Aviation Administration (FAA) to be in command of (and totally responsible for the safety of) a plane full of passengers, in almost any kind of weather or other situation.

\section{STATEMENT OF PROBLEM}

Presently in the United States commercial pilot applicants are not required to have any training in or knowledge of aerobatics, which includes recovering an aircraft from unusual flight attitudes and accelerations. Sometimes airplanes encounter weather, turbulence, or other factors that can cause an upset and loss of control. An upset occurs when the airplane is forced out of normal flight. In an aircraft that has departed from normal flight, the flight controls respond differently, and if a pilot is not familiar with the proper recovery procedures (which can be learned by performing aerobatics), an accident can result. "An airplane is designed to rotate around each of its three axes [three-dimensional motion]. Isn't it then reasonable to assume that a pilot trained to control an airplane throughout these rotations is a safer pilot?" (Cole, 1976). 


\section{PURPOSE OF STUDY}

In furtherance of aviation safety, this research will help to determine if the current US pilot population would embrace mandatory aerobatic from an authorized instructor for the issuance of a commercial pilot certificate. Since there has been no prior research on this subject, the purpose of this research is to determine whether pilots are or are not in favor of mandatory aerobatic training. No attempt will be made to determine how much training or what should be included in such training.

\section{HYPOTHESIS}

Pilot attitudes would be favorable towards mandatory aerobatic training for the issuance of a U.S. commercial pilot license. Pilots have a vested interest in improving both their own safety and that of the entire industry.

\section{THEORETICAL FRAMEWORK}

Traditionally during initial civilian pilot training, instructors teach their students the "Decide" model (FAA-H-8083-9). This model is a conceptual framework of how to make effective decisions in the aviation environment. This model has the following steps: Detect the fact that a change has occurred, Estimate the need to react, Choose a desirable outcome, Identify necessary actions, Do the necessary actions, and Evaluate the effects. The model is rather cumbersome initially, but as pilots gain experience, they generally complete several steps concurrently, and thus reaction and decision time are lessened. The Decide Model is related to aviation safety in that a pilot in an extreme unusual aircraft attitude would be unable to successfully use the model past the "Identify" step. If a pilot does not know or cannot do the actions required to recover his or her aircraft from an extreme unusual attitude, that pilot is no longer in control. Being able to identify an unsafe situation only utilizes the model halfway. A safe outcome is dependent on a successful completion of the DECIDE model.
According to the NTSB, maneuvering flight is one of the largest contributors to fatal accidents (NTSB, 2003). Maneuvering flight is a flight regime where aerobatic knowledge and skill may be necessary to the successful outcome of a flight. If pilots had aerobatic knowledge and skill, they would be more likely to successfully complete the Decide Model in some unsafe maneuvering flight situations where lack of aerobatic experience might otherwise prove fatal.

\section{ASSUMPTIONS}

In the US, pilots generally are assumed to earn pilot certificates and ratings in the following order: Student Pilot, Private Pilot, Instrument Rating, Commercial Pilot, Multi Engine Rating, Certified Flight Instructor, Certified Flight Instructor-Instrument, Certified Flight Instructor-Multi-Engine \& Instrument, Airline Transport Pilot. This order results from the required aeronautical experience for each certificate or rating under 14CFR FAR 61. Flight Schools operating under 14CFR FAR 141 generally grant certificates and ratings in the same order, but with less aeronautical experience due to an agreement with the FAA to follow a strict training syllabus with concurrent classroom instruction.

Another important assumption to the relevance of this study is that most students are generally trained in non-aerobatic aircraft and thus lack any sort of aerobatic skill in their aeronautical experience.

\section{LIMITATIONS}

An attitudinal survey was used to gather the data to determine whether the current pilot population would embrace mandatory aerobatic training. An informal pilot study was done to determine the validity and reliability of the study after Institutional Review Board approval, and the researcher determined that the independently designed survey was appropriate to use. However, due to a small sample size and the use of a convenience sample, the data are less robust than data collected from a larger random sample. 


\section{REVIEW OF LITERATURE}

\section{BACKGROUND}

An aircraft has three axes of motion, and three separate flight controls are used to move the aircraft about these three axes. Fore and aft motions of the control column control the pitch (up and down movements of the nose) of the aircraft. Sideways movements of the column, as in turning an automobile, control roll (side-toside leanings). Depressing either rudder pedal controls yaw, which can be described as a skidding, fishtailing movement of the rear end of the aircraft.

What exactly is aerobatics? Aerobatics is defined in two ways. First, aerobatics is defined as any "intentional maneuver involving an abrupt change in an aircraft's attitude, an abnormal attitude, or abnormal acceleration, not necessary for normal flight" (14 CFR 91.303). Second, when the pitch attitude, or nose up-anddown, of an airplane exceeds 30 degrees (up or down), and when the bank, or side-to-side leanings of an airplane exceeds 60 degrees, the occupants of the aircraft must wear parachutes (14 CFR 91.307(c

Although no formal studies have been done on the relationship between aerobatic training and aviation safety, an informal survey of readers of the on-line publication Avweb were asked their thoughts on aerobatic training (Avweb, 2002). Statistics from over 800 reader responses indicated 71 percent of the respondents were in favor of aerobatic training included in primary training (private pilot certification).

Indirect sources combine to support aerobatic's role in increasing aviation safety as well. Industry professionals have been noticing a lack of basic stick-and-rudder skills in pilots today (Machado, 2002). This lack of stick and rudder skills is thought to be a result of the general decline of experience among pilots (Machado, 2002; Wells, 1997). Stick-andrudder skills are physical skills the pilot uses in controlling his or her aircraft.

The decline in experience among pilots mentioned by Machado and Wells could be the result of many factors, but the economic conditions of the past few years have encouraged many instructor pilots to leave the profession as soon as they have enough experience to be employed by an airline (Wells, 1997). A number of years ago a relatively stable instructor force existed; a highly experienced cadre with very good stick and rudder skills. However, these instructors gradually retired, and with the current expansion of air carriers' new hire pilots' average experience levels are decreasing (Wells, 1997).

\section{PROBLEM HISTORY}

Currently, pilots become instructors soon after becoming commercial pilots in order to build flight time and make money until they can qualify for a higher paying pilot job. The minimum requirements for being an instructor pilot are quite minimal: Instructor pilots need only have a commercial pilots certificate with an instrument rating, which corresponds to a minimum of 250 flight hours (14CFR 61.183). This same pilot is also qualified to be a pilot crewmember on any jet airliner (14CFR 121.437). Historically, commercial air carriers have stipulated their pilots have more experience than the minimums required by the Federal Aviation Regulations, but the rapid expansion of air carriers has reduced this previously required experience (Wells, 1997). These low time instructor pilots generally do not have the stick and rudder experience to pass along to their students, resulting in loss of skills in new students over time (Machado, 2000).

How do pilots develop stick and rudder skills? There are two primary ways: One is by flying aircraft long enough to develop an intimate feel for the necessary control pressures, and the other is by learning aerobatics. The first way, as recent research by Machado and Wells has illustrated, is not happening. Perhaps things will change in the future, but right now the second method looks best for increasing stick and rudder skills in new commercial pilots.

The U.S. military flight training programs use low time instructor pilots like their civilian counterparts, but the military requires aerobatic training as a part of their curriculum (Millbrooke, 1999). The military views aerobatic training as essential to producing safe pilots. In all branches of military aviation, 
aerobatics is introduced early in the training as a core building block of an aviator's skills (Millbrooke, 1999). If both militarily trained pilots and civilian trained pilots are eligible to apply for the same commercial pilot license, why the disparity in training?

Since the current trend of low time pilots working as instructors and commercial flight crews is forecast to continue, the low skill level of these pilots needs to be addressed by the Federal Aviation Administration as a potential safety issue.

\section{COST ANALYSIS}

Admittedly, the proposal of mandatory aerobatic training will entail some costs to the affected pilots. There are no Federal Aviation Regulations addressing the elements of aerobatic instruction. FAR 23 addresses airworthiness requirements for aerobatic aircraft, and FAR 91.303 defines operational regulations for aerobatics, but the current customer must set his or her own standards. An informal look at aerobatic flight instruction providers conducted late in 2002 indicated aerobatic flight training cost to average $\$ 200.00$ per hour for aircraft plus instructor, with an average range of $\$ 179.00$ to $\$ 240.00$ per hour. The data used to compile this cost was from a selected few states (Arizona, California, Florida, Massachusetts, and Texas) representing a fairly large pilot population geographically.

Customers may access the International Aerobatic Club's website free of charge at http://www.iac.org/begin/schools.html and obtain a registry of aerobatic flight schools and their costs and services. Some aerobatic training programs have a very structured syllabus, and others have only an aircraft and instructor and will tailor the training to fit the customer.

The overall cost of aerobatic training is influenced by the type of trainer used, the reputation and geographic location of the school, and the experience of the instructor. Although the per-hour cost may seem higher when compared to traditional flight training, recognize that you'll be gaining a tremendous amount of new knowledge in a relatively short time. The techniques learned will improve your other flying skills immeasurably and likely could save your life someday (Stowell, 2002).

The cost of obtaining the aerobatic training itself reflects only a part of the entire economic burden on the affected pilots. Travel time and expense to get to the training facility and other expenses will vary greatly for each customer. However, considering that persons training to become commercial pilots have already invested large amounts of money in their education, the added burden of this aerobatic training and all added expenses remains quite small, comparatively. The average cost of training for a commercial pilot certificate ranges from $\$ 25,000$ to $\$ 37,200$ (2002 dollars), depending on the curriculum. Aerobatic training at \$200 per hour for three hours, for example, costs $\$ 600$ dollars. [At present there is no data available on how much aerobatic training is required to train a pilot to proficiency. More research needs to be done in this area.] Add on ancillary expenses and a liberal estimate of $\$ 1000$ dollars results. This $\$ 1000$ dollars increases the total cost of a commercial pilot's training expenses by only three percent.

Will this increase in cost increase aviation safety significantly? Unfortunately, measuring aviation safety is quite difficult. Accident data, for example, is a poor measure of aviation safety because accidents and fatality rates themselves have no predictive powers (Wells, 1997). Other data measuring risk exposure can have similar problems due to lack of a common denominator. Thus, a way to justify a $3 \%$ (or more) cost increase in flight training for U.S. commercial pilot applicants must be determined using some other method.

\section{METHODOLOGY}

\section{INTRODUCTION}

The question addressed is: "To what extent would the current pilot population embrace required aerobatic training for commercial pilot certification?" A survey having both qualitative and quantitative measures was used to gather data related to the research question. Several statistical tools were then used to determine demographics, to measure the reliability of the survey, to analyze 
the results, and finally to correlate the results with the research question.

\section{POPULATION}

The population this study is relevant to includes all US commercial pilots and airline transport pilots (airline transport pilots must previously have obtained a commercial pilot certificate). Private pilots are not included in the study because of their generally lower level of aeronautical experience. Commercial pilots are assumed to be more aware of their own flying abilities, due to the requisite aeronautical experience. Thus, the commercial pilots' attitudes would be more reliable than lower time pilots' attitudes, although the results would benefit the entire pilot population.

\section{SAMPLE}

The sample included 31 civilian commercial pilots, military-trained commercial pilots, and instructor pilots (instructor pilots are required to be commercial pilots). The minimum criterion for participation was a commercial pilot license because only commercial pilots can operate aircraft engaged in operations for compensation. Thus, they have greater responsibility than a pilot flying solely for pleasure. Also, since commercial pilots have a minimum of 250 hours of flight time, they are more aware of their own flying abilities than a lower time non-commercial pilot.

\section{INSTRUMENT}

A Likert scaled survey with forced response items (no neutral choice) was given to a convenience sample. The survey addressed the subjects' attitudes on eight quantitative measures, and two open response qualitative response questions. Descriptive quantitative statistics and qualitative analysis allows more thorough analysis of the data (Sirkin, 1999). A more robust measure is accomplished by using both quantitative and qualitative instruments (Wiggens \& Stevens, 1999).

\section{DATA COLLECTION METHODS}

The principal investigator distributed the survey to participants over a four-week period at airports around the Midwest. Participant selection was random, performed by asking anonymous pilots if they were commercial pilots and, if they were, requesting their participation in the survey.

Pilots at airports are not necessarily geographically fixed samples. They can be from all around the U.S., having flown in to a specific airport for many different reasons. There are generally a variety of commercial operations represented as well, from airline pilot to agricultural pilot to instructor pilot.

The pilots were given the surveys and completed them in a quiet, private place so as to minimize distractions. The investigator left the room during the survey administration to minimize influencing the subject.

\section{PROTECTION OF HUMAN SUBJECTS}

An Institutional Review Board first approved the survey. The surveys were totally anonymous, so there was no anticipated risk to the subjects or their aviation careers. The subjects had the option of keeping the information sheet attached to the survey (see appendix) to reference if they had any future questions regarding the survey or the data resulting from it. A subject's participation in the survey assumed the subject's consent.

The surveys and records will be stored in the principal investigator's locked filing cabinet for three years (starting February 15, 2003), and at the end of that period destroyed by shredding. The principal investigator was the only researcher involved in the project.

\section{INSTRUMENT RELIABILITY AND VALIDITY}

An initial pilot study conducted on the survey indicated reliability and validity over a widely diverse test group of industry experts: a minimum time 250 hour commercial pilot, a 1,500 hour instructor pilot, a 3,000 hour military fighter pilot, and a 15,000 hour airline pilot all successfully interpreted the survey's intent and 
predicted the scores of other pilot study participants based on their flight experience.

A convenience sample of 31 commercial pilots was used to gather the necessary data. Since the research is preliminary-only determining if aerobatic training would be beneficial to the safety of the aviation industryand does not address how much, what type, etc. of the training, a small sample representing all commercial pilot occupations seemed appropriate.

For the purpose of this study, significance levels of $\mathrm{P}<.05$ and alpha levels of $>0.7$ are considered significant and reliable, respectively. These levels are appropriate for an attitudinal survey (Sirkin, 1999).

A Cronbach's Alpha internal reliability test was performed on the survey instrument, yielding an alpha value of .996. This strong value, obtained using a relatively small sample size, indicates that the instrument is indeed satisfactory.

\section{QUANTITATIVE DATA ANALYSIS}

After preliminary data analysis, the decision was made to separate the responses into three separate groups: Those pilots with no aerobatic experience; those with less than ten hours of aerobatic experience; and those with more than ten hours of aerobatic experience. (See Table 1 for more demographic details). An Independent Sample Analysis of Variance (ANOVA) was performed on the data, yielding a significance level of $\mathrm{P}<.001$ (see tables 2 and 3). Further, a Tukey Honestly Significant Difference (HSD) test was performed to compare the individual groups' significance levels (see Table 4). Finally, a Pearson Product Moment Correlation (Pearson's r) was performed to determine the correlation of pilot's individual mean confidence index with their aerobatic experience (see Table 5) .

Table 1

Demographics of Pilot Groups

\begin{tabular}{|l|c|c|c|}
\hline \multicolumn{1}{|c|}{ Group } & $\begin{array}{c}\text { Mean } \\
\text { Flight } \\
\text { Hours }\end{array}$ & $\begin{array}{c}\text { Mean } \\
\text { Aerobatic } \\
\text { Hours }\end{array}$ & $\begin{array}{c}\text { Mean } \\
\text { Confidence } \\
\text { Score* }\end{array}$ \\
\hline $\begin{array}{l}\text { 0 hours of Aerobatic } \\
\text { Experience }\end{array}$ & 865 & 0 & 2.46 \\
\hline $\begin{array}{l}\text { Less than 10 hours of } \\
\text { Aerobatic Experience }\end{array}$ & 523 & 3.9 & 3.05 \\
\hline $\begin{array}{l}\text { Greater than 10 hours of } \\
\text { Aerobatic Experience }\end{array}$ & 7,206 & 134 & 3.50 \\
\hline
\end{tabular}

*Scores closer to 4.00 indicate greater confidence values

Table one breaks down the responses into three groups: those with zero hours of aerobatic experience, those with less than ten hours of aerobatic experience, and those with more than ten hours of aerobatic experience. The mean flight hours, aerobatic hours and confidence score are then given for each group. The mean confidence score was calculated by computing the mean of each survey's raw score, separated by group (see table 2). 
Table 2

Data Summary for Analysis of Variance (ANOVA) Calculation

\begin{tabular}{|c|c|c|c|c|}
\hline & $\begin{array}{c}\text { 0 hours aerobatic } \\
\text { experience }\end{array}$ & $\begin{array}{c}\text { Less than 10 hours } \\
\text { aerobatic experience }\end{array}$ & $\begin{array}{c}\text { Greater than 10 hours } \\
\text { aerobatic experience }\end{array}$ & Total \\
\hline $\mathrm{N}$ & 12 & 11 & 8 & 28 \\
\hline Sum of X & 29.5764 & 33.5995 & 3.5 & 64 \\
\hline Mean of X & 2.4647 & 3.0545 & 19.375 & 2.0645 \\
\hline Sum of $\mathrm{X}^{2}$ & 78.9375 & 43.8438 & 0.1964 & 0.3342 \\
\hline Variance of X & 0.1288 & 0.18121 & 0.4432 & .05781 \\
\hline $\begin{array}{c}\text { Std.Deviation } \\
\text { of X }\end{array}$ & 0.3589 & 0.4267 & 0.1567 & 0.1038 \\
\hline Std. Error of X & 0.1036 & 0.1287 & & \\
\hline
\end{tabular}

Table two describes the various measurements of the confidence scores. The groups are segregated by the number of aerobatic hours as before. $\mathrm{N}$ is the number of surveys in each group. $\mathrm{X}$ is the confidence value, which was obtained by summation of each survey's total score from the Likert scale.

Table 3

Analysis of Variance (ANOVA) Results

\begin{tabular}{|l|c|r|r|r|r|}
\hline & SS & df & MS & F & P \\
\hline $\begin{array}{l}\text { Treatment } \\
\text { (between groups) }\end{array}$ & 5.41 & 2 & 2.71 & 16.94 & $<.0001$ \\
\hline Error & 4.61 & 28 & 0.16 & & \\
\hline Total & 10.03 & 30 & & & \\
\hline
\end{tabular}

Table three shows the values used in calculating the One-Way Analysis of Variance on the confidence values of the groups from table two. The obtained value of $\mathrm{P}$ is shown to be less than .0001 .

Table 4

Tukey Honestly Significant Difference (HSD) Results

\begin{tabular}{|ll|l|}
\hline M1 vs. M2 & $\mathrm{P}<.05$ & M1 = mean of Group 1 \\
M1 vs. M3 & $\mathrm{P}<.01$ & M2 = mean of Group 2 \\
M2 vs. M3 & $\mathrm{P}<.01$ & M3 = mean of Group 3. \\
\hline & & $\begin{array}{l}\text { HSD = the absolute difference } \\
\text { between any two sample means } \\
\end{array}$ \\
& & $\begin{array}{l}\text { required for significance at the } \\
\text { designated level (.05 in this case). }\end{array}$ \\
\hline
\end{tabular}

Table four takes the ANOVA one step further, testing the significance between each group rather than all three groups together. Each group is significantly different from each other group, with a $\mathrm{P}$ value of less than .05 in all cases. 
Table 5

Pearson Product Moment Correlation Coefficient (Pearson's r)

\begin{tabular}{|c|c|c|}
\hline & $\mathrm{X}^{*}$ & $\overline{\mathrm{Y}^{* *}}$ \\
\hline $\mathrm{N}$ & 31 & 31 \\
\hline Mean & 36.0645 & 2.9355 \\
\hline Variance & 5436.379 & 0.3467 \\
\hline Std. Dev. & 73.7318 & 0.5888 \\
\hline Std. Error & 13.2426 & 0.1058 \\
\hline 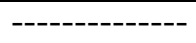 & |------০---- & 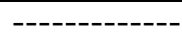 \\
\hline$r$ & .5544 & \\
\hline $\mathrm{r}^{2}$ & .3074 & \\
\hline Slope & .0044 & \\
\hline Y-intercept & 2.7768 & \\
\hline $\begin{array}{l}\text { Std. Error } \\
\text { of Estimate }\end{array}$ & .4984 & \\
\hline $\mathrm{t}$ & 3.59 & \\
\hline$\overline{\mathrm{df}}$ & 29 & \\
\hline P (1-tailed) & .000601 & \\
\hline P (2-tailed) & .001202 & \\
\hline
\end{tabular}

Table five shows the Pearson's $\mathrm{r}$ value of .5544 with a $\mathrm{P}$ (2-tailed) value of .001 , where $\mathrm{X}$ represents aerobatic hours and $\mathrm{Y}$ represents individual confidence values. Confidence values should approach 4.00 as aerobatic hours increase.

\section{QUALITATIVE DATA ANALYSIS}

A Grounded Theory analysis (Glaser \& Strauss, 1967) was performed on the qualitative response items. 20 subjects of the 31 total elected to complete the qualitative response items. The data for the qualitative analysis was separated into three groups in the same manner as the quantitative data (pilots without aerobatic experience, pilots with less than ten hours of aerobatic experience, and pilots with greater than ten hours of aerobatic experience).

The results from thematic coding of the qualitative data are summarized below:

1. Pilots with zero aerobatic experience expressed increased confidence levels and a reduction in trepidation as a possible result of aerobatic training.

2. Pilots with less than 10 hours of aerobatic experience noted the differences between theory and simulation (talking about versus actually performing aerobatics), reducing trepidation, and increasing confidence levels all as a result of aerobatic training.

3. Pilots with more than 10 hours of aerobatic training mentioned only the increase in confidence levels as a result of aerobatic training.

4. Two respondents (10\% of the sample) mentioned that not all pilots want to engage in aerobatic training, due to various reasons (motion sickness, fear, etc.)

5. Of the 20 qualitative respondents, $50 \%$ of them indicated aerobatic training would or has increased their confidence level. This supports the notion that aerobatic experience increases pilot confidence levels.

\section{DISCUSSION}

The purpose of this study was to determine if the U.S. pilot population would embrace mandatory aerobatic training for the 
issuance of a commercial pilot license. No such training is required of the civilian pilot population presently, and the sources mentioned herein suggest that aerobatic training would be beneficial to pilot skills and decision making processes.

Since the majority of the present U.S. civilian pilot population receives no aerobatic training, the hypothesis is that if the next generation of commercial pilots received aerobatic training, some difference in industry safety statistics would exist. The extent of the effect on ndustry safety was not addressed in this study.

Using a survey designed to measure quantitative and qualitative attitudinal data on a 4-item forced-response Likert scale, the investigator measured the correlation of pilots' aerobatic experience with their confidence levels. Also measured were open-response items addressing comments or concerns voiced by the subjects. Cronbach's alpha test was performed to determine the reliability of the survey. With that, the subjects were divided into three groups according to their aerobatic experience, and an independent sample ANOVA was used to calculate the differences of the mean confidence levels between the groups. Further, the Tukey HSD test was used to test the individual group means with each other. Glasier and Strauss' Grounded Theory Analysis was used to measure the qualitative data.

\section{CONCLUSION}

The findings of both the quantitative and qualitative analyses support the hypothesis that pilots would be in favor of mandatory aerobatic training for the issuance of a US commercial pilot's license. The participants all indicated that aerobatic training would or has made them safer pilots, in addition to generally increasing their overall confidence levels.

There was a significant correlation between the number of aerobatic hours a pilot has and his or her confidence level, with more aerobatic hours correlating with greater confidence levels. Thus, the current commercial pilot population in the US would embrace mandatory aerobatic training, and believes such training would improve the aviation industry's safety record.

Although no attempt was made to determine the amount or type of aerobatic training for the proposed mandatory training, the survey data indicated a significant difference in confidence levels between those with no aerobatic training and those with 1 to 10 hours of aerobatic experience. A significant difference also exists between the group with 1 to 10 hours of aerobatic experience and the group with more than 10 hours of aerobatic experience. However, in the group with more than 10 hours of aerobatic experience, the smallest amount of aerobatic training had 25 hours of aerobatic experience. Thus, even though a significant difference exists between the groups, the number of hours where confidence levels become significantly greater is unclear. It appears to be somewhere between 10 and 25 hours, but more research needs to be done in this area to make a strong determination. 


\section{REFERENCES}

ASA-02-FR-AM-BK. (2002). Far/Aim 2002. U.S. Department of Transportation: From Title 14 of the Code of Federal Regulations (14CFR). Newcastle: Aviation Supplies \& Academics, Inc.

Avweb Group [On-line] (2002). Question of the Week. Available: http://www.avweb.com/newswire/8_49b/qotw/181824-1.html

Cole, D.. (1976). Roll Around a Point. Milwaukee: Ken Cook Company.

Cole, D.. (1970). Conquest of Lines and Symmetry. Milwaukee: Ken Cook Transnational.

DeLacerda, F. (2001). Peak Performance for Aerobatics. Ames: Iowa State University Press.

FAA-H-8083-9 (1999). Aviation Instructor's Handbook. U.S. Department of Transportation. Oklahoma City: Federal Aviation Administration.

Glaser, B. G, and Strauss, A. L. (1967). The Discovery of Grounded Theory; Strategies for Qualitative Research. Chicago: Aldine Publishing Co.

Goeters, K-M. (1998). Aviation Psychology: A science and a Profession. Brookfield: Ashgate Publishing Limited.

International Aerobatic Club [On-line] (2002). Available: http://www.iac.org

Jeppesen Sanderson, Inc (1998). Private Pilot Manual. Printed in Canada.

Kershner, W.. (1985).The Flight Instructor's Manual, $2^{\text {nd }}$ Edition. Ames: Iowa State University Press.

Machado, R.. (2002, January 4). Today’s Pilots Lack Basic Stick-and-Rudder Skills. GA News, 28.

Medore, Lt. Col. A., USAFR. (No date available). Primary Aerobatic Flight Training with Military Techniques. (No city available):Aviation Book Company.

Millbrooke, A.. (1999). Aviation History. Englewood, Co: Jeppeson Sanderson.

National Transportation Safety Board. (2003). Aviation Accident Database. [On-Line]. Available: http://www.ntsb.gov (2003, March 3).

Sirkin, R. M.. (1999). Statistics for the Social Sciences, $2^{\text {nd }}$ edition. California: Sage Publications, Inc.

Stowell, R..(1996). Emergncy Maneuvers Training. Ventura: Rich Stowell Consulting.

Stowell, R. (2002). How to Shop for Quality Aerobatic Training. [On-line]. Available: http://www.richstowell.com/howto.html. (2002, November 15).

Telfer, R. \& Biggs, J. (1988). The Psychology of Flight Training. Ames: Iowa State University Press.

U.S. Dept. of Transportation, Federal Aviation Administration. FAA-S-8081-12A. (1997). Commercial Pilot for Airplane Single and Multiengine Land Practical Test Standards. Newcastle: Aviation Supplies \& Academics, Inc. 
Wells, A. (1997). Commercial Aviation Safety, Second Edition. New York: Mcgraw- Hill.Wiggens, Mark, \& Stevens, Catherine (1999). Aviation Social Science: Research Methods in Practice. Brookfield, Vermont: Ashgate Publishing Company 